\title{
Antioxidant effect of muscle relaxants (vecuronium, rocuronium) on the rabbit abdominal aortic endothelial damage induced by reactive oxygen species
}

\author{
Ji Seon Jeong, Jung Kook Suh, Eun Sun Cho, Dong Won Kim, and Mi Ae Jeong \\ Department of Anesthesilogy and Pain Medicine, School of Medicine, Hanyang University, Seoul, Korea
}

Background: Muscle relaxants induce vascular smooth muscle relaxation by inducing synthesis of the prostaglandins that influence vasomotor tone. However, the effects of muscle relaxants on endothelial cells and tissues following injury by reactive oxygen species (ROS) are unclear. We tested the effects of the muscle relaxants vecuronium and rocuronium on impaired acetylcholine (ACh)-induced relaxation following induction of ROS in rabbit aorta in vitro.

Methods: Isolated rabbit abdominal aortic ring segments were pretreated with vecuronium or rocuronium at $10^{-4}$, $3 \times 10^{-4}, 10^{-3}$ or $3 \times 10^{-3} \mathrm{M}$, with or without inhibitors of $\mathrm{Cu} / \mathrm{Zn}$ superoxide dismutase (diethyldithiocarbamate; DETCA, $0.8 \mathrm{mM}$ ) or catalase (3-amino-1,2,4-triazole; 3AT, $50 \mathrm{mM}$ ). All groups of aortic rings were then exposed to ROS generated by electrolysis in the organ bath medium (Krebs-Henseleit solution). The effects of vecuronium and rocuronium on ROS-induced impairment of relaxation induced by ACh $\left(10^{-6} \mathrm{M}\right)$ were assessed.

Results: Aortic rings treated with vecuronium or rocuronium at $10^{-4}, 3 \times 10^{-4}, 10^{-3}$ or $3 \times 10^{-3} \mathrm{M}$ preserved the capacity for ACh-induced endothelial relaxation following ROS exposure in a dose-dependent manner. Pretreatment with DETCA partially inhibited the protective effects of vecuronium and rocuronium on ACh-induced relaxation $(\mathrm{P}<0.001)$, but pretreatment with $3 \mathrm{AT}$ had no effect.

Conclusions: Muscle relaxants protected the endothelium in isolated rabbit abdominal aorta from free-radical injury in a dose-dependent manner. These results suggest that vecuronium and rocuronium may act as superoxide anion scavengers. (Korean J Anesthesiol 2013; 65: 552-558)

Key Words: Antioxidant effect, Reactive oxygen species, Rocuronium, Vecuronium.

Received: July 3, 2013. Revised: 1st, August 6, 2013; 2nd, August 8, 2013. Accepted: August 8, 2013.

Corresponding author: Jung Kook Suh, M.D., Ph.D., Department of Anesthesiology and Pain Medicine, School of Medicine, Hanyang University Hospital, 17, Haengdang-dong, Sungdong-gu, Seoul 133-792, Korea. Tel: 82-2-2290-8680, Fax: 82-2-2299-8692, E-mail: jksuh@hanyang.ac.kr This article is a Doctor's Thesis by Ji Seon Jeong.

(c) This is an open-access article distributed under the terms of the Creative Commons Attribution Non-Commercial License (http:// creativecommons.org/licenses/by-nc/3.0/), which permits unrestricted non-commercial use, distribution, and reproduction in any medium, provided the original work is properly cited. 


\section{Introduction}

Vascular tone develops through the regulated contraction and relaxation of vascular smooth muscle cells (VSMCs). Factors that regulate vasodilation include nitric oxide (NO), endotheliumderived hyperpolarizing factor (epoxyeicosatrienoic acid) and prostacyclin, while thromboxane $\mathrm{A}_{2}$, endothelin 1 , angiotensin II and reactive oxygen species (ROS) regulate vasoconstriction [1]. Injury by ROS may adversely affect endothelial function in part through inhibition of NO synthesis in endothelial cells [2], an effect observed as augmented vasoconstriction.

ROS form in the course of metabolic processes involving oxygen, as in mitochondrial oxidative phosphorylation, in which glucose is oxidized to form water, carbon dioxide and high-energy metabolites (ATP, NADPH). Cells of the immune system generate ROS in the destruction of pathogenic cells and microorganisms, and liver cytochrome systems activate molecular oxygen in the biotransformation of drugs, nutrients, hormones and xenobiotic compounds. Platelet aggregation and wound healing involve free-radical biochemistry. ROS may also form spontaneously, given the ubiquitous presence of molecular oxygen, reducing agents and transition metals such as iron and copper in living systems, and through radiation exposure. The intermediate forms of oxygen activation, including superoxide radical $\left(\mathrm{O}_{2}^{-}\right)$, hydrogen peroxide $\left(\mathrm{H}_{2} \mathrm{O}_{2}\right)$ and hydroxyl radical $\left(\mathrm{OH}^{*}\right)$, may also induce tissue injury (oxidative stress) [3].

Within the circulatory system, ROS within the physiologic range of concentrations serve to regulate VSMC contraction and relaxation [4]. At increasing concentrations, however, ROS may contribute to the pathological effects of ischemia-reperfusion, inflammation, hypertension, diabetes mellitus and atherosclerosis, through oxidative injury to blood vessels $[5,6]$.

Cell injury mediated by ischemia-reperfusion or inflammation may be reduced by the antioxidant effects of intravascular or inhalation anesthetics [7]. Local anesthetics such as lidocaine also display antioxidant activity [8]. However, the potential antioxidant effects of muscle relaxants on vascular endothelium have received little attention as compared to the direct relaxation effects of these drugs on VSMCs through induction of prostaglandin synthesis $[9,10]$.

To investigate the antioxidant activities of muscle relaxants, we tested the effects of vecuronium and rocuronium on the impairment of acetylcholine (ACh)-induced relaxation in rabbit aorta following exposure to ROS, and we probed the mechanism of these effects.

\section{Materials and Methods}

\section{Preparation of aortic ring segments and recording}

The regulatory committee for the use of animals in research
Laboratory Animal Committee at Hanyang University approved this study. Twenty-seven male New Zealand White rabbits, 2.0$2.5 \mathrm{~kg}$, (KOATECH, Pyeongtaek, Korea) were anesthetized with 3-5 vol\% sevoflurane in $4 \mathrm{~L} / \mathrm{min}$ of $100 \%$ oxygen. Heparin 600 $\mathrm{IU} / \mathrm{kg}$ was administered through auricular marginal vein. After 10 minutes, we exsanguinated the rabbits by cutting the carotid artery.

The abdominal aorta was carefully excised and placed on a petri dish containing Krebs-Henseleit solution (K-H solution) containing [in mM]: $\mathrm{NaCl} 120.0, \mathrm{NaHCO}_{3} 25.0, \mathrm{KCl} 5.0, \mathrm{MgSO}_{4}$ $1.2, \mathrm{CaCl}_{2} 2.5, \mathrm{NaH}_{2} \mathrm{PO}_{4} 1.4$, and glucose 11.0 at $4^{\circ} \mathrm{C}$. Fat and surrounding connective tissue were trimmed away from the aorta without injury to vascular smooth muscle and endothelial cells, and the aorta was sectioned into rings of 2 to $3 \mathrm{~mm}$ in length.

Each aortic ring segment was placed between two L-shaped stainless steel hooks in an organ bath containing $5 \mathrm{ml} \mathrm{K}-\mathrm{H}$ solution and maintained at $37 \pm 0.5^{\circ} \mathrm{C}$. The organ bath was continuously supplied with a mixture of $95 \%$ oxygen and $5 \%$ carbon dioxide. The lower hook was fixed to the organ bath and the upper one to a force displacement transducer (TSD125C; BIOPAC Systems Inc., Goleta, CA, USA). Isometric tension of vascular smooth muscle was continuously recorded on a personal computer by a data acquisition system (MP100 system, BIOPAC Systems Inc., Goleta, CA, USA) by means of a transducer amplifier (DA100C, BIOPAC Systems Inc., USA). The aortic ring segments were equilibrated with the organ bath system for 90 minutes. During this period, the K-H solution was exchanged every 15 minutes and resting tension was maintained at $2 \mathrm{~g}$.

\section{Assessment of endothelial integrity in abdominal aortic ring segments}

After equilibration, the status of endothelial tissue in the aortic ring segment was determined as the percent tension reduction induced by serial administration of ACh at $3 \times 10^{-8}$, $10^{-7}, 3 \times 10^{-7}$ and $10^{-6} \mathrm{M}$ following precontraction induced by norepinephrine (NE) at $10^{-6} \mathrm{M}[11,12]$. The aortic ring segments showing relaxation greater than $70 \%$ were considered to be intact, and were used for these experiments [13].

\section{Exposure of aortic ring segments to ROS}

Reactive oxygen species were generated by electrolysis in the solution bathing the aortic ring segments. Two circular platinum wire electrodes $(7.5 \mathrm{~mm})$ were placed near the bottom of the organ bath, and a constant current of $15 \mathrm{~mA}$ was applied for 35 seconds. A space separation of $1 \mathrm{~cm}$ between electrode and the aortic ring segments effectively prevented direct electrical stimulation. 


\section{Control group experiment}

After confirming preservation of vascular endothelium and allowing the system to equilibrate for 15 minutes, we generated ROS by electrolysis and replaced the K-H solution. Using NE $\left(10^{-6} \mathrm{M}\right)$ and ACh $\left(3 \times 10^{-8}, 10^{-7}, 3 \times 10^{-7}, 10^{-6} \mathrm{M}\right)$, as described above, the aortic ring segments were then contracted and relaxed. The percent tension reduction induced by ACh following precontraction with $\mathrm{NE}$ was adopted as the control value.

\section{Effect of ROS on endothelial response following vecuronium or rocuronium pretreatment}

After confirming preservation of vascular endothelium and allowing 15 minutes for equilibration, vecuronium or rocuronium was introduced into the organ bath at concentrations of $10^{-4}$, $3 \times 10^{-4}, 10^{-3}$ or $3 \times 10^{-3} \mathrm{M}$. After $15 \mathrm{~min}$, we generated ROS by electrolysis and changed the K-H solution. The aortic ring segments were contracted and relaxed (see above), and the percent relaxation was calculated as the experimental value.

\section{Effect of ROS on endothelial response following antioxidant enzyme inhibition}

Endogenous antioxidant capacity in the isolated aortic ring segments was reduced using diethyldithiocarbamate (DETCA) as an inhibitor of $\mathrm{Cu} / \mathrm{Zn}$ superoxide dismutase (SOD) and 3-amino-1,2,4-triazole (3AT) as catalase inhibitor. After confirming endothelial integrity in aortic ring segments and allowing 15 minutes for equilibration, DETCA $(0.8 \mathrm{mM})$ or 3AT (50 $\mathrm{mM}$ ) was introduced into the organ bath for 30 minutes. Either vecuronium $\left(3 \times 10^{-3} \mathrm{M}\right)$ or rocuronium $\left(3 \times 10^{-3} \mathrm{M}\right)$ was then added for 15 minutes and electrolysis was initiated and the K-H solution was changed. The aortic ring segments were contracted and relaxed as described above, and the percent relaxation was calculated as the experimental value.

Concentrations of DETCA reported in various studies range from $0.1 \mathrm{mM}$ to $1.0 \mathrm{mM}$. We used DETCA at $0.8 \mathrm{mM}$, because this produced significant inhibition of the ACh-induced relaxation.

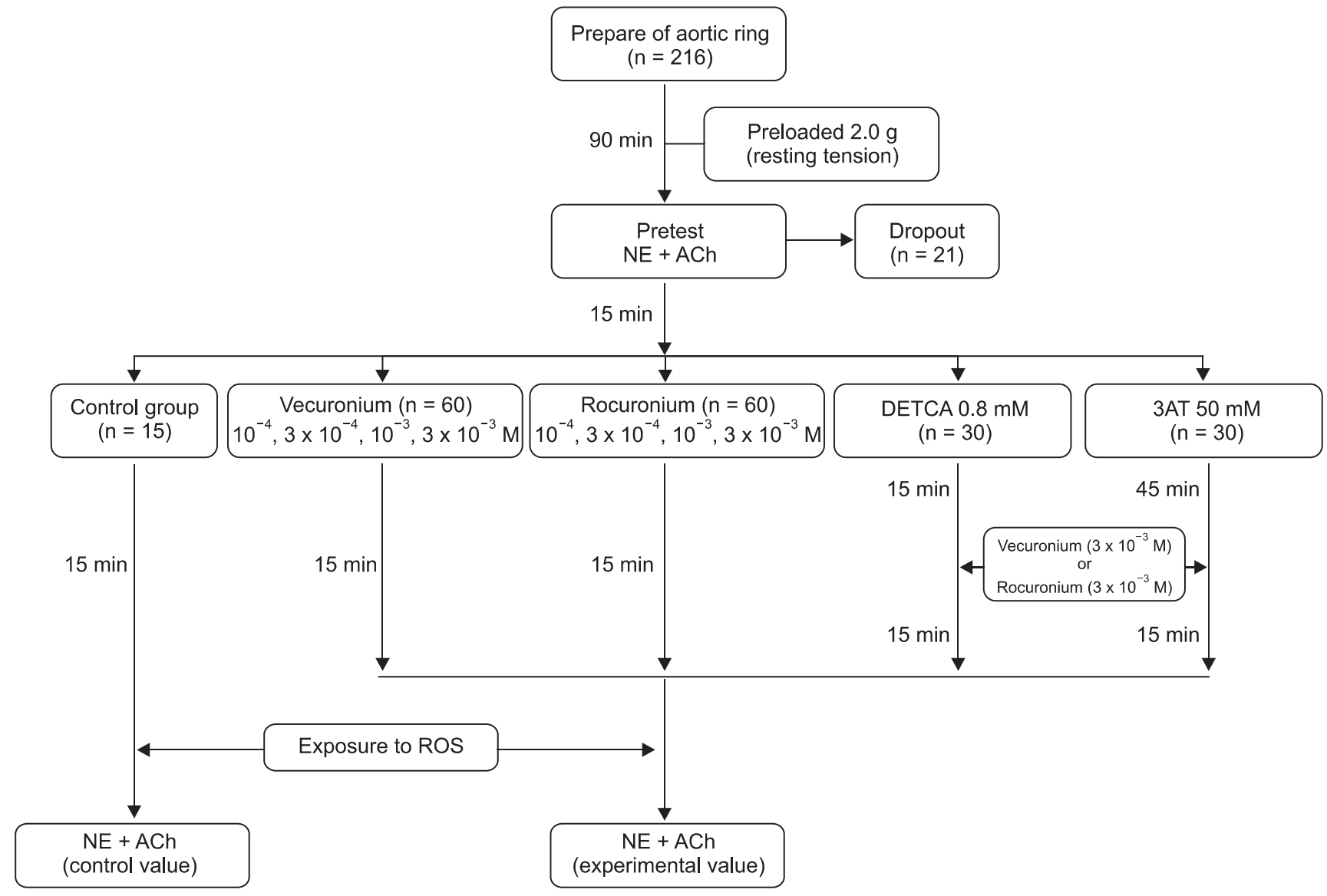

Fig. 1. Experimental design. NE: norepinephrine, ACh: acetylcholine, DETCA: diethyldithiocarbamate, 3AT: 3-amino-1,2,4-triazole, ROS: reactive oxygen species. 


\section{Drugs}

The NE, ACh, DETCA and 3AT used in these experiments were purchased from Sigma Chemical Company, St Louis, MO, USA, and vecuronium and rocuronium were purchased from N.V. Organon, Oss, The Netherlands. All of these drugs were dissolved in deionized water on the day of the experiment, and portions not used were kept frozen at $-20^{\circ} \mathrm{C}$.

\section{Statistical analysis}

Statistical calculations were performed using PASW 18.0 (SPSS Inc., Chicago, IL, USA). We used one-way ANOVA for the effects of vecuronium and rocuronium on ACh-induced relaxation following ROS-induced vascular injury, and Dunnett's test was performed as post-hoc. An unpaired t-test was used to compare the percent vascular relaxation between groups pretreated with DETCA or 3AT and a non-pretreated group. All data were presented as the mean \pm error deviation, and a $P$ value less than 0.05 was considered to be statistically significant.

\section{Results}

From 27 rabbits, we obtained 8 abdominal aortic ring segments per rabbit, after excluding 20 segments that did not relax more than $70 \%$. Twelve experimental groups, with 15 aortic ring segments per group, were assigned including 8 groups cor-

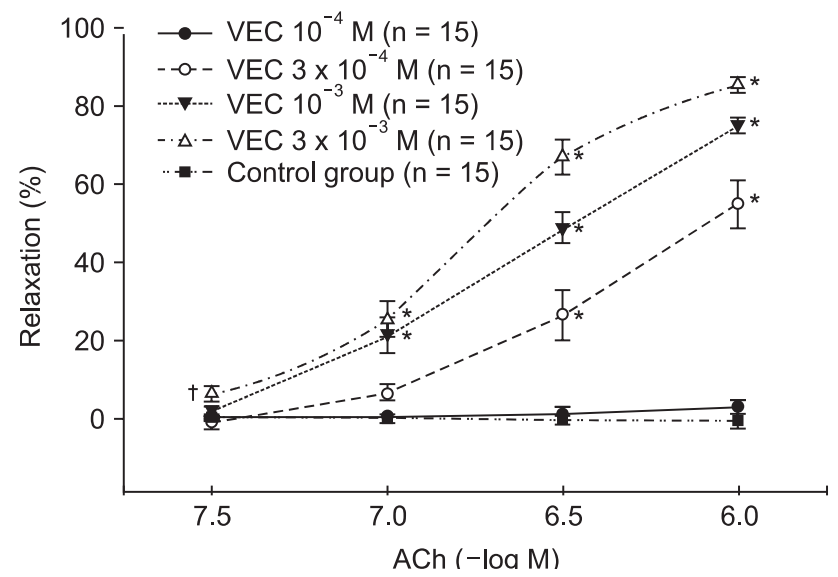

Fig. 2. Effect of vecuronium (VEC, $10^{-4}, 3 \times 10^{-4}, 10^{-3}, 3 \times 10^{-3} \mathrm{M}$ ) on acetylcholine ( $\mathrm{ACh}, 10^{-6} \mathrm{M}$ )-induced relaxation in endotheliumintact rabbit aortic ring segments exposed to reactive oxygen species. Norepinephrine $\left(10^{-6} \mathrm{M}\right)$-induced contractions are indicated as follows: $100 \%=6.3 \pm 1.2 \mathrm{~g}(\mathrm{n}=15), 100 \%=6.1 \pm 1.4 \mathrm{~g}(\mathrm{n}=15), 100 \%=5.6 \pm$ $0.7 \mathrm{~g}(\mathrm{n}=15)$ and $100 \%=6.7 \pm 1.1 \mathrm{~g}(\mathrm{n}=15)$ for untreated aortic ring segments and ring segments treated with $10^{-4} \mathrm{M}, 3 \times 10^{-4} \mathrm{M}, 10^{-3} \mathrm{M}$ and $3 \times 10^{-3} \mathrm{M}$ vecuronium, respectively. Values are presented as the mean \pm error. $\mathrm{N}$ indicates the number of aortic ring segments. $* \mathrm{~A} \mathrm{P}$ value less than 0.001 indicates a significant difference from control group. ${ }^{\dagger} \mathrm{A} \mathrm{P}$ value less than 0.05 indicates a significant difference from control group. responding to the concentrations of vecuronium or rocuronium $\left(10^{-4}, 3 \times 10^{-4}, 10^{-3}, 3 \times 10^{-3} \mathrm{M}\right)$ and 2 groups each for the DET$\mathrm{CA}$ and $3 \mathrm{AT}$ pretreatments (Fig. 1).

The control group consisted of 15 ring segments, not exposed to any pretreatment, in which we measured the percent relaxation after exposure to ROS. The control value $(\mathrm{n}=15)$ was $-0.38 \pm 2.0 \%$.

\section{Effects of muscle relaxant pretreatment on vascular endothelium after ROS-induced injury}

Following exposure to ROS generated in the organ bath, aortic ring segments did not display the relaxation response to ACh $10^{-6} \mathrm{M}$. In contrast, groups of aortic rings pretreated with vecuronium $\left(10^{-4}, 3 \times 10^{-4}, 10^{-3}, 3 \times 10^{-3} \mathrm{M}\right)$ showed a dosedependent preservation of the ACh-induced relaxation response (Fig. 2). Groups pretreated with vecuronium $3 \times 10^{-4}, 10^{-3}$ and 3 $\times 10^{-3} \mathrm{M}$ differed significantly from control groups in the AChinduced relaxation response following ROS exposure $(\mathrm{P}<0.001)$ (Fig. 2). Rocuronium pretreatment at $3 \times 10^{-4}, 10^{-3}$ and $3 \times 10^{-3}$ $\mathrm{M}$ produced a response similar to that of vecuronium $(\mathrm{P}<0.001)$ (Fig. 3).

\section{Effect of antioxidant enzyme inhibition on protection from ROS-induced endothelial injury}

Following exposure to ROS, aortic rings pretreated with

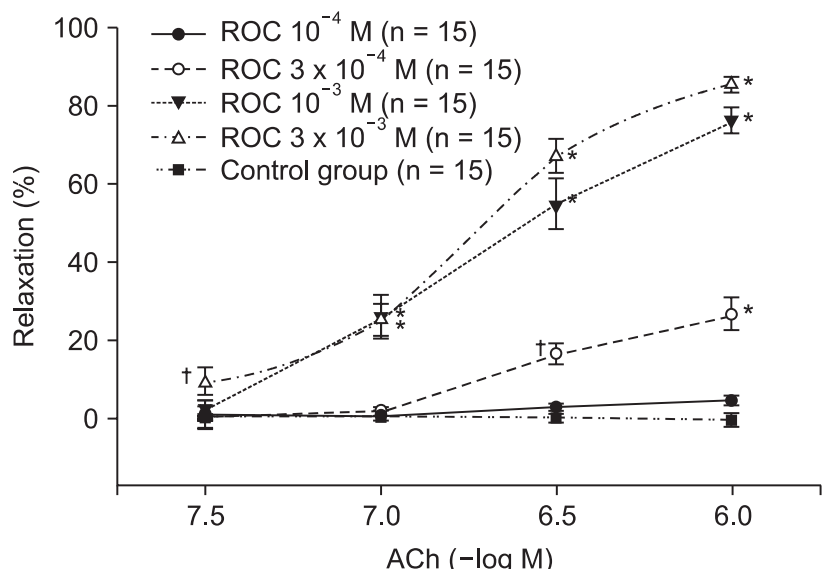

Fig. 3. Effect of rocuronium (ROC, $10^{-4}, 3 \times 10^{-4}, 10^{-3}, 3 \times 10^{-3} \mathrm{M}$ ) on acetylcholine ( $\mathrm{ACh}, 10^{-6} \mathrm{M}$ )-induced relaxation in rabbit aortic ring segments exposed to reactive oxygen species. Norepinephrine $\left(10^{-6} \mathrm{M}\right)$ induced contraction values given as $100 \%=6.4 \pm 0.5 \mathrm{~g}(\mathrm{n}=15), 100 \%$ $=6.4 \pm 1.5 \mathrm{~g}(\mathrm{n}=15), 100 \%=5.9 \pm 0.9 \mathrm{~g}(\mathrm{n}=15)$ and $100 \%=6.2 \pm$ $0.6 \mathrm{~g}(\mathrm{n}=15)$ correspond to untreated rabbit aortic ring segments and ring segments treated with $10^{-4} \mathrm{M}, 3 \times 10^{-4} \mathrm{M}, 10^{-3} \mathrm{M}$ and $3 \times 10^{-3} \mathrm{M}$ rocuronium, respectively. Values are presented as the mean \pm error. $\mathrm{N}$ indicates the number of isolated rabbit aortic ring segments. $* \mathrm{P}<0.001$ compared to control. ${ }^{\dagger} \mathrm{P}<0.05$ compared to control. 


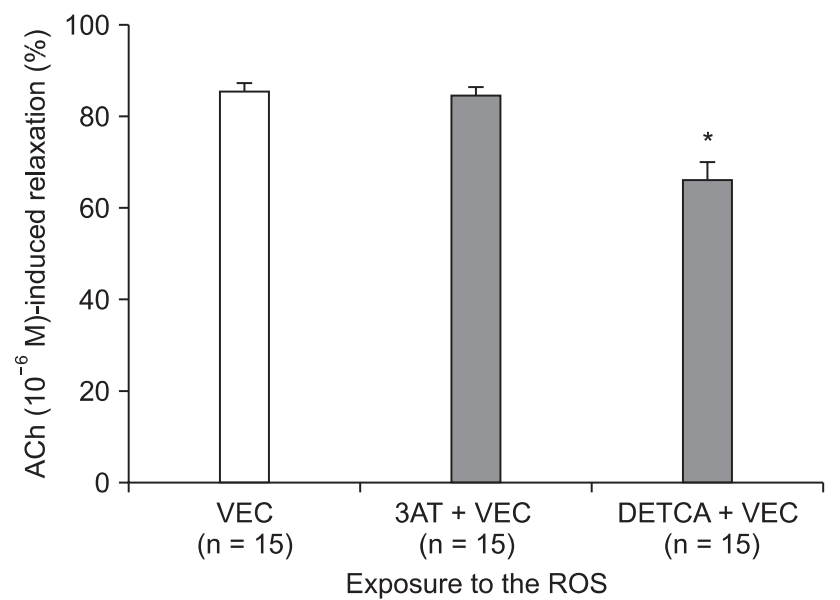

Fig. 4. The effect of vecuronium (VEC, $3 \times 10^{-3} \mathrm{M}$ ) alone, VEC combined with 3-amino-1,2,4-triazole (3AT), and VEC plus diethyldithiocarbamate (DETCA) on acetylcholine (ACh, $10^{-6} \mathrm{M}$ )-induced relaxation in endothelium-intact rabbit aortic ring segments exposed to reactive oxygen species. Values represent mean values \pm S.E. $\mathrm{N}$ indicates the number of aortic ring segments. $* \mathrm{P}<0.001$ compared to VEC group.

DETCA + vecuronium $\left(3 \times 10^{-3} \mathrm{M}\right)$ showed a reduction in the extent of ACh-induced relaxation as compared to the group pretreated with vecuronium $\left(3 \times 10^{-3} \mathrm{M}\right)$ only $(66.0 \pm 3.7 \%$ compared with $85.4 \pm 1.9 \% ; \mathrm{P}<0.001$ ) (Fig. 4). However, the groups pretreated with vecuronium $\left(3 \times 10^{-3} \mathrm{M}\right)+3 \mathrm{AT}$ and vecuronium $\left(3 \times 10^{-3} \mathrm{M}\right)$ only did not differ significantly. The relaxation response in aortic rings pretreated with DETCA + rocuronium $3 \times 10^{-3} \mathrm{M}(72.4 \pm 2.5 \%)$ was also reduced as compared with rocuronium $3 \times 10^{-3} \mathrm{M}$ only $(85.5 \pm 1.8 \%)(\mathrm{P}<0.001)$ (Fig. 5). However, the groups pretreated with $3 \mathrm{AT}+$ rocuronium $\left(3 \times 10^{-3} \mathrm{M}\right)$ and rocuronium $\left(3 \times 10^{-3} \mathrm{M}\right)$ only did not differ in the $\mathrm{ACh}$-induced relaxation response following ROS exposure $(86.9 \pm 1.7 \%)$.

\section{Discussion}

Through experiments with rabbit abdominal aortic ring segments, we knew that the muscle relaxants rocuronium and vecuronium attenuated the ROS-induced impairment of AChinduced relaxation of the vascular endothelium. Based on these observations, we hypothesized that the muscle relaxants exert antioxidant effects. In the present study, the superoxide dismutase inhibitor DETCA inhibited the protective effect of vecuronium and rocuronium on the ACh-induced relaxation response following ROS exposure, while the catalase inhibitor 3-AT had no effect.

The non-depolarizing muscle relaxants include primarily the aminosteroid and benzylisoquinolinium compounds. These drugs act as antagonists at the nicotinic ACh receptor of the neuromuscular junction through competitive interaction with $\mathrm{ACh}$;

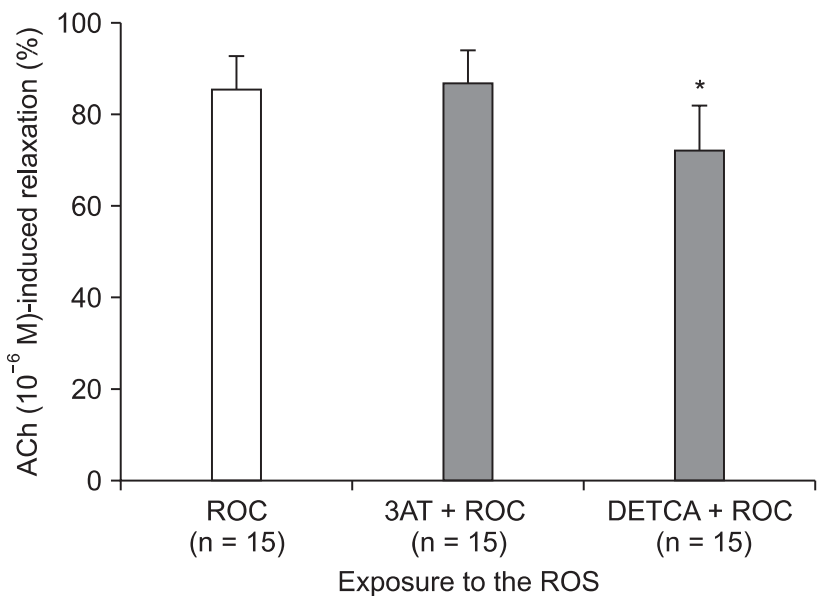

Fig. 5. The effect of rocuronium (ROC, $3 \times 10^{-3} \mathrm{M}$ ) alone, ROC combined with 3-amino-1,2,4-triazole (3AT), and ROC plus diethyldithiocarbamate (DETCA) on acetylcholine (ACh, $10^{-6} \mathrm{M}$ )-induced relaxation in endothelium-intact rabbit aortic ring segments exposed to reactive oxygen species. Values are presented as mean values \pm S.E. $N$ indicates the number of aortic ring segments. ${ }^{*} \mathrm{P}<0.001$ compared to the ROC group.

however, they exert no effects on VSMCs [14]. Vecuronium and rocuronium are aminosteroids.

Previous studies demonstrate the effects of muscle relaxants on vascular smooth muscle using the aortic ring segment model $[9,10,15]$; however, those studies concern the direct effects of the drugs on vascular smooth muscle contraction and relaxation, and describe effects in the coronary artery of the dog [15] and pig [10], and thoracic aorta of the rat [9]. In those studies, the vascular effects of the muscle relaxants varied according to the type and concentration of drug. The relaxation effects of the drugs in vascular smooth muscle increased in the following order: pancuronium $<$ rocuronium $<$ vecuronium [9]. As the relaxation effects in vascular smooth muscle did not depend on the status of the vascular endothelium, any effect of the drug on vascular endothelium will not be related to its potency in vascular smooth muscle relaxation $[9,10,15]$.

The present study was conducted not to confirm direct effects of muscle relaxants on vascular smooth muscle, but to investigate the effects of the drugs on the vascular endothelial function following ROS-induced injury. The ACh-induced relaxation of vascular smooth muscle occurs through guanylyl cyclase activation and NO generation in vascular endothelium [16]. Following ROS-induced injury to vascular endothelium, the dose-dependent preservation of ACh-induced relaxation by vecuronium or rocuronium implies that the muscle relaxants act as ROS scavengers in this setting.

Reactive oxygen species perform vital regulatory functions as second messengers in cell growth, proliferation, endothelial barrier function, vasorelaxation, and vascular remodeling [17]. These species arise not only in vascular endothelium, but also 
in vascular media or adventitia. ROS may participate in the induction of an endothelium-dependent or independent vascular relaxation effect through modulation of NO signaling [18]. Physiologically, the superoxide radical $\left(\mathrm{O}_{2}{ }^{--}\right)$and $\mathrm{H}_{2} \mathrm{O}_{2}$ play prominent roles [3]. Important ROS include $\mathrm{O}_{2}{ }^{-}, \mathrm{OH}^{*}$, peroxyl (ROO'), hydroperoxyl $\left(\mathrm{HO}_{2}{ }^{\circ}\right)$ radicals and non-radical oxidizing agents that readily convert to $\mathrm{H}_{2} \mathrm{O}_{2}$, hypochlorous acid or ozone [19]. Superoxide dismutase converts the superoxide anion to hydrogen peroxide, which is reduced to $\mathrm{H}_{2} \mathrm{O}$ and oxygen by catalase or glutathione peroxidase. Hydrogen peroxide or superoxide anion may also arise through the Fenton reaction $\left(\mathrm{Fe}^{2+}+\right.$ $\left.\mathrm{H}_{2} \mathrm{O}_{2} \rightarrow \mathrm{Fe}^{3+}+\mathrm{OH}^{\cdot}+\mathrm{OH}^{-}\right)$reacting with metal like copper or Haber-Weiss reaction $\left(\mathrm{O}_{2}{ }^{--}+\mathrm{H}_{2} \mathrm{O}_{2} \rightarrow \mathrm{OH}^{\cdot}+\mathrm{OH}^{-}+\mathrm{O}_{2}\right)$ [1]. In biological systems, a reducing compound such as ascorbate, in conjunction with the Fenton reaction, may catalyze a cycle of destructive interaction with tissue components. Oxygen activation at the time of ischemia-reperfusion induces vascular endothelial injury [20], with significant clinical effects in the heart, brain and blood vessels [21-23].

In the present study, the SOD inhibitor DETCA appeared to antagonize the protective effect of vecuronium and rocuronium on ROS-induced injury to aortic ring segments. An inhibitor of catalase, $3 \mathrm{~A}$, did not show similar effect. These results imply that vecuronium and rocuronium may exert antioxidant effects through superoxide-anion scavenging.

ACh-induced relaxation may represent not only the action of $\mathrm{NO}$, but also or alternatively an increase in intracellular $\mathrm{Ca}^{2+}$ induced by cyclic guanosine monophosphate [24] or the inhibition of nicotinamide adenine dinucelotide phosphate oxidase [25]. These pathways present mechanisms by which the non-depolarizing muscle relaxant might influence ACh-induced relaxation in addition or alternative to superoxide anion scavenging.

Electrolysis in physiologic salt solution has been previously shown to generate ROS, including $\mathrm{O}_{2}{ }^{--}, \mathrm{H}_{2} \mathrm{O}_{2}, \mathrm{OH}^{\cdot}$ radicals [26]. The K-H solution used in the physiologic salt solution may contain ascorbic acid $\left(1.1 \times 10^{-4} \mathrm{M}\right)$, which may act either as an antioxidant or as potentiator of the Fenton reaction, depending on ambient conditions [27]. Hence, we did not add ascorbic acid to the K-H solution.

Following the electrolysis, the K-H solution was exchanged thereby removing ROS; thus the inhibition of Ach-induced vascular relaxation must have occurred through modification of the vascular endothelium, rather than by $\mathrm{NO}$ inactivation.

In a clinical setting, the doses of muscle relaxants administered are unlikely to exert antioxidant effects. Peak rocuronium concentration just after intravenous administration is $7 \mu \mathrm{g} / \mathrm{ml}$ [28], and a plasma vecuronium concentration of $0.1 \mu \mathrm{g} / \mathrm{ml}$ induces 50\% neuromuscular blockade [29]. The corresponding plasma concentrations of vecuronium and rocuronium at these times are $1.6 \times 10^{-7}$ and $1.1 \times 10^{-5} \mathrm{M}$, respectively. The lowest concentration we used for these drugs in the present experiments was $10^{-4} \mathrm{M}$. At this drug concentration, the degree of ACh-induced relaxation following exposure to ROS was $2.8 \pm$ $1.9 \%$ for pretreatment with vecuronium and $4.8 \pm 1.1 \%$ for rocuronium. These values represent very weak antioxidant activity in either case.

Although we did not directly quantify the ROS generated by electrolysis, we feel that our results clearly demonstrate the antioxidant effects of these muscle relaxants. Similarly, although the muscle relaxant appears to act as a superoxide radical scavenger, we did not quantify the dose-response relationship between ROS and either drug. The rocuronium was dissolved a solution containing sodium acetate trihydrate, sodium chloride and glacial acetic acid, which may potentially have influenced our findings; however, we did not perform a solvent control.

As our principal finding, we report that the aminosteroid muscle relaxants vecuronium and rocuronium dose-dependently preserved the capacity for ACh-induced relaxation in rabbit abdominal aortic ring segments exposed to ROS. In this protective effect, the drugs may perform as superoxide anion scavengers.

\section{References}

1. Félétou M, Vanhoutte PM. Endothelial dysfunction: a multifaceted disorder (The Wiggers Award Lecture). Am J Physiol Heart Circ Physiol 2006; 291: H985-1002.

2. Förstermann U. Nitric oxide and oxidative stress in vascular disease. Pflugers Arch 2010; 459: 923-39.

3. Queisser N, Fazeli G, Schupp N. Superoxide anion and hydrogen peroxide-induced signaling and damage in angiotensin II and aldosterone action. Biol Chem 2010; 391: 1265-79.

4. Touyz RM. Reactive oxygen species as mediators of calcium signaling by angiotensin II: implications in vascular physiology and pathophysiology. Antioxid Redox Signal 2005; 7: 1302-14.

5. Wilcox CS. Reactive oxygen species: roles in blood pressure and kidney function. Curr Hypertens Rep 2002; 4: 160-6.

6. Bulkley GB. Free radical-mediated reperfusion injury: a selective review. Br J Cancer Suppl 1987; 8: 66-73.

7. Musacchio E, Rizzoli V, Bianchi M, Bindoli A, Galzigna L. Antioxidant action of propofol on liver microsomes, mitochondria and brain synaptosomes in the rat. Pharmacol Toxicol 1991; 69: 75-7. 
8. de Klaver MJ, Weingart GS, Obrig TG, Rich GF. Local anesthetic-induced protection against lipopolysaccharide-induced injury in endothelial cells: the role of mitochondrial adenosine triphosphate-sensitive potassium channels. Anesth Analg 2006; 102: 1108-13.

9. Gursoy S, Bagcivan I, Durmus N, Kaygusuz K, Kol IO, Yildirim S, et al. Investigation of the relaxant effects of pancuronium, rocuronium, vecuronium and mivacurium on rat thoracic aorta. Eur J Anaesthesiol 2009; 26: 155-9.

10. Klockgether-Radke AP, Haemmerle A, Kettler D, Hellige G. Do muscle relaxants influence vascular tone in isolated coronary artery segments? Eur J Anaesthesiol 2000; 17: 481-4.

11. Lee JM, Suh JK, Jeong JS, Cho SY, Kim DW. Antioxidant effect of lidocaine and procaine on reactive oxygen species-induced endothelial dysfunction in the rabbit abdominal aorta. Korean J Anesthesiol 2010; 59: 104-10.

12. Kim JH, Kim H, Kim YH, Chung WS, Suh JK, Kim SJ. Antioxidant effect of captopril and enalapril on reactive oxygen species-induced endothelial dysfunction in the rabbit abdominal aorta. Korean J Thorac Cardiovasc Surg 2013; 46: 14-21.

13. Park WK, Lynch C 3rd, Johns RA. Effects of propofol and thiopental in isolated rat aorta and pulmonary artery. Anesthesiology 1992; 77: 956-63.

14. Savarese JJ, Lowenstein E. The name of the game: no anesthesia by cookbook. Anesthesiology 1985; 62: 703-5.

15. Sai Y, Ayajiki K, Okamura T, Nosaka S, Toda N. Comparison of the effects of pancuronium and vecuronium in canine coronary and renal arteries. Anesthesiology 1998; 88: 165-71.

16. Lam TY, Seto SW, Lau YM, Au LS, Kwan YW, Ngai SM, et al. Impairment of the vascular relaxation and differential expression of caveolin-1 of the aorta of diabetic $+\mathrm{db} /+\mathrm{db}$ mice. Eur J Pharmacol 2006; 546: 134-41.

17. Pober JS, Min W, Bradley JR. Mechanisms of endothelial dysfunction, injury, and death. Annu Rev Pathol 2009; 4: 71-95.

18. Münzel T, Daiber A, Ullrich V, Mülsch A. Vascular consequences of endothelial nitric oxide synthase uncoupling for the activity and expression of the soluble guanylyl cyclase and the cGMP-dependent protein kinase. Arterioscler Thromb Vasc Biol 2005; 25: 1551-7.

19. Bayir H. Reactive oxygen species. Crit Care Med 2005; 33(12 Suppl): S498-501.

20. Chen X, Gillis CN. Effect of free radicals on pulmonary vascular response to acetylcholine. J Appl Physiol (1985) 1991; 71: 821-5.

21. Kato R, Foëx P. Myocardial protection by anesthetic agents against ischemia-reperfusion injury: an update for anesthesiologists. Can J Anaesth 2002; 49: 777-91.

22. Hwang YS, Shin CY, Huh Y, Ryu JH. Hwangryun-Hae-Dok-tang (Huanglian-Jie-Du-Tang) extract and its constituents reduce ischemiareperfusion brain injury and neutrophil infiltration in rats. Life Sci 2002; 71: 2105-17.

23. Brodsky SV, Yamamoto T, Tada T, Kim B, Chen J, Kajiya F, et al. Endothelial dysfunction in ischemic acute renal failure: rescue by transplanted endothelial cells. Am J Physiol Renal Physiol 2002; 282: F1140-9.

24. Brophy CM, Knoepp L, Xin J, Pollock JS. Functional expression of NOS 1 in vascular smooth muscle. Am J Physiol Heart Circ Physiol 2000; 278: H991-7.

25. Zhang G, Zhang F, Muh R, Yi F, Chalupsky K, Cai H, et al. Autocrine/paracrine pattern of superoxide production through NAD(P)H oxidase in coronary arterial myocytes. Am J Physiol Heart Circ Physiol 2007; 292: H483-95.

26. Gumusel B, Tel BC, Demirdamar R, Sahin-Erdemli I. Reactive oxygen species-induced impairment of endothelium-dependent relaxation in rat aortic rings: protection by L-arginine. Eur J Pharmacol 1996; 306: 107-12.

27. Pirbudak L, Balat O, Cekmen M, Ugur MG, Aygun S, Oner U. Effect of ascorbic acid on surgical stress response in gynecologic surgery. Int J Clin Pract 2004; 58: 928-31.

28. Wierda JM, Proost JH, Schiere S, Hommes FD. Pharmacokinetics and pharmacokinetic/dynamic relationship of rocuronium bromide in humans. Eur J Anaesthesiol Suppl 1994; 9: 66-74.

29. Cronnelly R, Fisher DM, Miller RD, Gencarelli P, Nguyen-Gruenke L, Castagnoli N Jr. Pharmacokinetics and pharmacodynamics of vecuronium (ORG NC45) and pancuronium in anesthetized humans. Anesthesiology 1983; 58: 405-8. 